REMLATE DE MLALIES

Campinas-SP, v.40, n.2, pp. 526-545, jul./dez. 2020

\title{
O discurso crítico de Pasolini e Fortini NAS PÁGINAS DE JORNAIS ${ }^{1}$
}

\author{
PAsolini's AND Fortini's Criticism \\ IN THE NEWSPAPERS
}

\author{
Cláudia Tavares Alves ${ }^{2}$
}

\begin{abstract}
Resumo: A partir de um questionamento acerca dos paradigmas de atuação crítica de Pier Paolo Pasolini e Franco Fortini, este artigo apresenta algumas linhas de reflexão sobre como ambos os escritores agiam enquanto figuras de intervenção pública. Para tanto, serão analisados momentos de interlocução estabelecida entre os dois através das páginas de jornais italianos, principalmente a partir do ano de 1968, quando divergências acabam por culminar no rompimento pessoal entre eles. Assim, a principal intenção desta análise é mostrar em que medida as formas de fazer crítica praticadas por Pasolini e Fortini ora se assemelham e ora se distinguem consideravelmente, o que acaba por revelar que, apesar de ambos terem motivações políticas muito próximas enquanto intelectuais marxistas-gramscianos, cada um deles traçou percursos bastante particulares.
\end{abstract}

Palavras-chave: Pier Paolo Pasolini; Franco Fortini; intelectual.

\begin{abstract}
Taking as a starting point the question of critical praxis in Pier Paolo Pasolini's and Franco Fortini's works, this essay inquiries into how both writers acted as figures of public intervention. For that, it analyses interlocutions established between both writers in the pages of Italian newspapers, especially after 1968, when their divergences led to the end of their friendship. This analysis' main intention is to show how the forms of the criticism practiced by Pasolini and Fortini, very similar at first sight, diverge in certain

\footnotetext{
${ }^{1}$ Este artigo é resultado da comunicação "O discurso crítico de Pasolini e Fortini”, apresentada no IV Encontro Pasoliniano, ocorrido em outubro de 2019, no Instituto de Estudos da Linguagem da Unicamp. Ele integra a pesquisa de doutorado "A importância de Pasolini no jornalismo italiano dos anos 1970" (processo no 2016/o7884-o, Fundação de Amparo à Pesquisa do Estado de São Paulo - Fapesp).

2 Doutora em Teoria e História Literária pela Universidade Estadual de Campinas (Unicamp), Brasil: <clautalves@gmail.com>.
} 
aspects; even though their political motivations as intellectuals, inspired by Marx and Gramsci, overlap, each writer took a very particular path.

Keywords: Pier Paolo Pasolini; Franco Fortini; Intellectual.

\section{ALGUMAS CONSIDERAÇÕES}

O que pode a palavra escrita? Essa pergunta, feita e refeita ao longo dos anos por diversos pensadores e pensadoras, aplicada a contextos igualmente diversos e particulares, parece nunca alcançar uma resposta definitiva. É uma pergunta em constante reformulação justamente por sua natureza resiliente: o gesto de elaborá-la vale por si só mais do que por seus resultados. Ainda assim, é pelo impulso que ela impele que acessamos aquilo que continua nos interessando e movendo. Nesse sentido, um possível caminho pode vir sugerido pelos versos do poeta português Manuel António Pina (2018, p. 16): "O que é feito das palavras senão as palavras?". A pergunta, que contém em si mesma sua resolução, parece apontar para o claro enigma de que com palavras fazem-se palavras. Mas é nas linhas seguintes do poema, publicado no livro Ainda não é o fim nem o princípio do mundo calma é apenas um pouco tarde, de 1974, que o questionamento inicial parece se desfazer: "Já não é possível dizer mais nada/ mas também não é possível ficar calado/ Eis o verdadeiro rosto do poema" (p. 16). Seguindo essa mesma linha, temos ainda a confissão inconfessável que João Cabral de Melo Neto (1982, p. 5) descreve em seu Museu de tudo, do mesmo ano de 1974, quando, diante da inutilidade de qualquer ação que se pratique ou se deixe de praticar, um artista só poderia reiteradamente escolher fazer - o que quer que seja -, afinal, "entre fazer e não fazer/ mais vale o inútil do fazer".

Quando nos deslocamos para refletir sobre essa pergunta a partir da tradição italiana, tal questionamento ganha, como é de se esperar, nuanças bastante particulares. Em conferência proferida em 1976 - e inédita até a publicação da coletânea Una pietra sopra, cuja primeira edição circulou em 1980 -, o romancista e ensaísta Italo Calvino recapitula brevemente seus anos de formação. Ali, lança mão de termos como "literatura" e "política" para pensar quais problemas eram fulcrais para ele e sua geração:

Os anos da minha juventude, a partir de 1945 e durante os anos Cinquenta e além, tiveram como problemas dominantes as relações entre o escritor e a política. Eu poderia dizer que toda discussão girava ao redor deste ponto. A 
minha geração poderia ser definida como aquela que começou a se ocupar da literatura e da política ao mesmo tempo (CALVINO, 2018, p. 347). ${ }^{3}$

Na apresentação intitulada "Usos políticos certos e errados da literatura", Calvino segue afirmando, no entanto, que naquele ano de 1976 a sensação era de vazio; vazio tanto de um projeto político, quanto de um projeto literário. Ou seja, o impulso que havia movido até então essa geração de escritores à qual ele pertencia, em busca de uma possibilidade de síntese ou conjugação entre as duas esferas, a literária e a política, parecia estar perdendo força de forma que o movimento não se sustentaria mais simplesmente por inércia.

Ao nos depararmos com a perspectiva de Calvino pensando os anos de 1970 na Itália, tomamos consciência de escritores para quem literatura e política afetam-se mutuamente - algo que traz implicações diretas para a pergunta sobre "o que" (ou "quanto") pode a palavra escrita. É nesse sentido que, para Pier Paolo Pasolini e Franco Fortini, dois dos grandes nomes que compõem essa geração de escritores italianos da segunda metade do século XX, a mesma pergunta se infla e rompe a fina película que define o que é ser poeta e o que é ser intelectual. Se para ambos acrescentarmos ao substantivo palavra o adjetivo política, teremos aí um sintagma que reorganiza, simultaneamente, aquelas perguntas e respostas de Pina e João Cabral: a impossibilidade ou a inutilidade da palavra não pode privá--la de ser pública e explícita, carregando em si mesma, ao mesmo tempo, um peso literário e um peso político.

Há, porém, divergências consideráveis entre as práticas de escrita dos dois italianos, isto é, a forma como ambos resolveram suas equações entre engajamento político e literatura, o que torna instigante uma investigação sobre suas atuações públicas. A atenção com a palavra e o que pode ser feito dela parecem ser dois dos nortes que guiam a produção poética e ensaística desses escritores. Existiria, pois, algo que os assemelharia nessa procura pelo uso preciso da língua como ação política no mundo. Entretanto, haveria também algo que os afastaria consideravelmente, colocando-os em direções opostas quando diante dessa procura. Sendo assim, a análise

\footnotetext{
3 "Gli anni della mia gioventù, a partire dal 1945 e per tutti gli anni Cinquanta e oltre, hanno avuto come problemi dominanti i rapporti tra lo scrittore e la politica. Potrei dire che ogni discussione girava intorno a questo punto. La mia generazione potrebbe essere definita come quella che ha cominciato a occuparsi di letteratura e di politica allo stesso tempo." Se não houver indicação em contrário, as traduções de citações são de responsabilidade da autora do artigo.
}

Remate de Males, Campinas-SP, v.40, n.2, pp. 526-545, jul./dez. 2020 - 528 
que se segue é movida pela constatação do que aproxima e ao mesmo tempo distancia a produção intelectual de Pasolini e Fortini, tentando reconstruir um possível traço entre eles. O principal objetivo é explorar, a partir de certas relações que se desenham, como a interlocução entre os dois escritores - nesse caso, vista pela ótica das dinâmicas de interlocução pública via jornais - é índice de um movimento de autorreflexão sobre o que um escritor intelectual, tomado por seus interesses literários e políticos, pode fazer quando se dá conta da dissolução do mundo como ele o conhece.

\section{PASOLINI E FORTINI EM DEBATE}

Em 10 de junho de 1974, Pasolini publicou o artigo "Os italianos não são mais os mesmos" ["Gli italiani non sono più quelli”], ${ }^{4}$ no jornal Corriere della Sera, em contribuição à coluna "Tribuna Aberta”. Analisando a vitória do "não" no plebiscito italiano sobre o divórcio, o qual decidira sobre a não revogação da lei Fortuna-Baslini ${ }^{5}$ - isto é, a lei que, em 1970, finalmente regulamentou o divórcio na Itália-, Pasolini expõe os conceitos de mutação antropológica ["mutazione" antropologica] e padronização cultural [omologazione "culturale"], ou seja, duas das formulações essenciais para as suas reflexões sobre a sociedade italiana daquele período. Os italianos não seriam mais os mesmos porque, segundo o escritor, estaria em curso uma mudança sistemática de valores sociais e culturais tão intensa a ponto de não ser mais possível distinguir um cidadão fascista de um cidadão antifascista, pois ambos seriam "culturalmente, psicologicamente e, o

\footnotetext{
4 "Gli italiani non sono più quelli" (Corriere della Sera, 10 de junho de 1974, pp. 1-2). Em Scritti corsari, o artigo recebeu o título de "Studio sulla rivoluzione antropologica in Italia" (PASOLINI, 1999, pp. 307-312); em Escritos corsários, "Estudo sobre a revolução antropológica na Itália” (PASOLINI, 2020, pp. 71-77). Os artigos de Pasolini reunidos na coletânea Scritti corsari serão citados a partir da edição da obra completa, presente no volume Saggi sulla politica e sulla società. Em português, as citações serão feitas a partir da tradução Escritos corsários, de Maria Betânia Amoroso, publicada em 2020.

${ }^{5}$ A ocasião, que ficou conhecida como referendum sul divorzio, foi o primeiro plebiscito da Itália republicana e tinha como objetivo realizar uma consulta pública sobre a lei Fortuna-Baslini, aprovada em dezembro de 1970 e que legislava sobre o matrimônio. Até então, o código civil italiano não permitia a dissolução de casamentos, por entender que não seria consentido reverter sacramentos. A existência de tal lei até 1970 revela de certa forma a força com que a Igreja Católica ainda imperava no país. Por outro lado, a promulgação da nova lei, que passa a entender o matrimônio como uma prática civil laica, transparece um momento de mudanças importantes para compreendermos os movimentos sociais e políticos dos anos 1970, na Itália, contexto ao qual pertencem Pasolini e Fortini.
} 
que é mais impressionante, fisicamente intercambiáveis" (PASOLINI, 2020, p. 75). ${ }^{6}$

A ocasião do plebiscito popular desperta em Pasolini uma reflexão profunda - e "a coragem intelectual de dizer" (PASOLINI, 2020, p. 73) acerca da derrota política (mais do que uma vitória) tanto do Vaticano, que era contra a manutenção da legalização do divórcio, quanto do Partido Comunista, que fazia campanha para que o plebiscito corroborasse a lei já existente. Na opinião do escritor, ambas as instituições não souberam compreender bem a transformação pela qual passava a sociedade italiana. A vitória do "não", nesse sentido, não seria sinônimo de um povo mais progressista, laico ou democrático, mas sim de um povo que cinicamente estava arremessando ao mar os seus valores tradicionais e católicos. A explicação para esse fenômeno, prossegue Pasolini, é que essa nova sociedade seria resultado de uma intensa mudança de valores motivada pela ideologia hedonista do consumo e pela falsa tolerância moderna, o que teria como consequência última "a passagem de uma cultura, feita do analfabetismo (o povo) e do humanismo esfarrapado (as classes médias) de uma organização cultural arcaica, à organização moderna da 'cultura de massa"' (PASOLINI, 2020, p. 74). ${ }^{7}$

O ponto central de sua argumentação é que tal mudança de valores, calcada no aburguesamento dos cidadãos, se afasta tanto do fascismo tradicional, quanto do progressismo socialista, e passa a unificar, homologar, padronizar culturalmente todo mundo, visto que "a matriz que gera todos os italianos passou a ser a mesma" (PASOLINI, 2020, p. 75). ${ }^{8}$ A conclusão fatal é que não seria mais possível diferenciar um italiano fascista de um antifascista, já que, de um ponto de vista cultural e antropológico, eles são iguais e a única forma de distingui-los seria pela nomeação verbal direta de tal diferença. Por todas essas razões, Pasolini questiona a comemoração ao redor de uma vitória política a qual, social e culturalmente, não representaria uma verdadeira vitória do socialismo e do progressismo.

Os desdobramentos dessa publicação, com as ideias lançadas nesse artigo sendo rebatidas por diversos outros intelectuais em diversos outros

\footnotetext{
6 "[...] culturalmente, psicologicamente e, quel che è più impressionante, fisicamente, interscambiabili” (PASOLINI, 1999, p. 310).

7 "[...] passaggio di una cultura, fatta di analfabetismo (il popolo) e di umanesimo cencioso (i ceti medi) da un'organizzazione culturale arcaica, all'organizzazione moderna della 'cultura di massa”' (PASOLINI, 1999, p. 309).

8 "La matrice che genera tutti gli italiani è ormai la stessa" (PASOLINI, 1999, p. 310).
}

Remate de Males, Campinas-SP, v.40, n.2, pp. 526-545, jul./dez. 2020 - 530 
jornais, perduraram por alguns meses. Uma das principais repercussões foi um debate proposto e publicado pelo periódico L'Espresso, em 23 de junho de 1974. Sob o título de "Nasceu uma criança: tem mais um fascista” [È nato un bimbo: c'è un fascista in più] e acompanhada por uma série de imagens de Pasolini progressivamente vestindo uma camisa até cobrir seu próprio rosto (Figura 1), a publicação aproveitou a atmosfera polêmica que se criou ao redor do artigo publicado no Corriere e reuniu importantes intelectuais para discuti-lo. Eram eles: os escritores Alberto Moravia, Leonardo Sciascia, Franco Fortini, o psicanalista Elvio Fachinelli e o filósofo e político italiano Lucio Colletti.

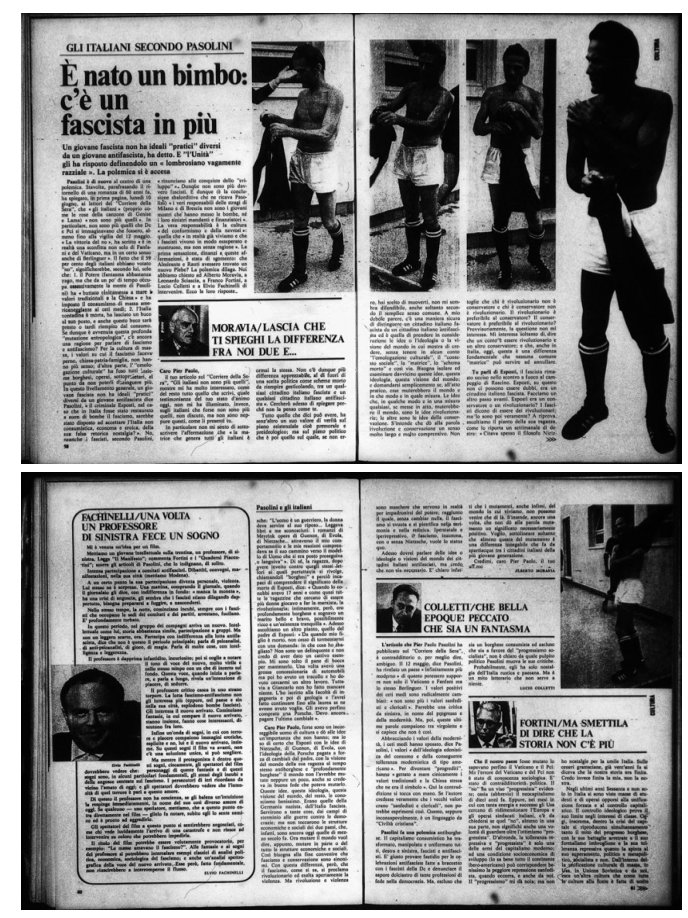




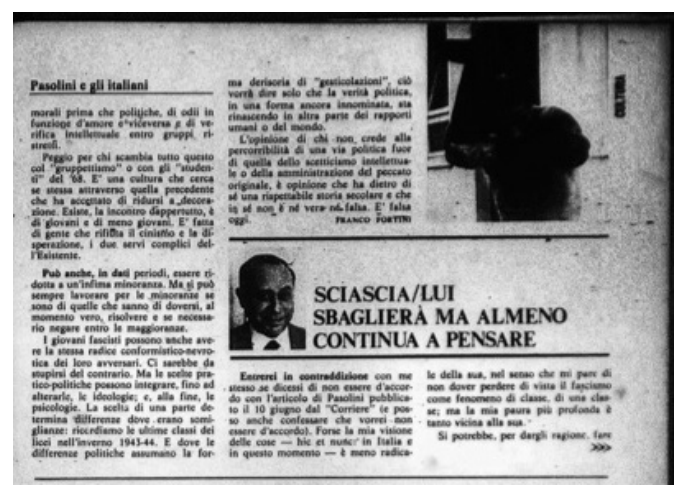

Figura 1 - "È nato un bimbo: c'è un fascista in piư"; debate no periódico L'Espresso

(MORAVIA et al., 1974).

Fonte: Cópias feitas pela autora.

Entre discordâncias e concordâncias, as quais são partes constitutivas da dinâmica de debates em jornais nessa época, ${ }^{9}$ a contribuição de Fortini - "Pare de dizer que a história não existe mais" [Ma smettila di dire che la storia non c'è più] (FORTINI, 1975, pp. 61-63) - chama a atenção por não nomear Pasolini, ainda que seu comentário esteja inserido em um contexto de resposta ao escritor. Porém, há em seu texto algumas referências que remontam a uma relação de interlocução entre os artigos dos dois autores: o verbo no imperativo, que aparece logo no título e que remete discursivamente a uma segunda pessoa; uma menção às "cinzas gramscianas", em referência ao poema "Le ceneri di Gramsci", escrito por Pasolini em 1954, no qual já se afirmava que "a história estava acabada”; ${ }^{10} \mathrm{e}$ ainda um sujeito genérico, indeterminado, presente na afirmação de que:

\footnotetext{
${ }_{9}^{9}$ O tema central da minha pesquisa de doutorado, "A importância de Pasolini no jornalismo italiano dos anos 1970", foi compreender essa dinâmica a partir dos escritos jornalísticos de Pasolini publicados nos anos de 1970, buscando mapear as principais forças de atuação nesse contexto. A leitura dos artigos pasolinianos a partir das interlocuções que eles estabeleciam com outros intelectuais revelou que debater ideias, via jornais, era uma característica intrínseca à ação de torná-las públicas em periódicos de grande e média circulação. Nesse sentido, é importante ter em mente que a interlocução entre Pasolini e Fortini, assim como entre tantos outros intelectuais, é constitutiva de uma atmosfera mais ampla, em que concordar ou discordar publicamente faz parte do exercício crítico e reflexivo a que eles estão dispostos a praticar.

${ }^{10}$ A expressão aparece nos versos: "Ma io, con il cuore cosciente/ di chi soltanto nella storia ha vita,/ potrò mai più con pura passione operare,/ se so che la nostra storia è finita?" (PASOLINI, 1976, p. 78). Na tradução de Maurício Santana Dias: "Mas eu, com o peito consciente/ de quem apenas na história tem vida,/ poderei agir com pura paixão ainda,/ se sei que nossa história aqui se finda?" (PASOLINI, 2015, p. 73).
} 
A opinião de quem não acredita na praticabilidade de uma via política fora daquela do ceticismo intelectual ou da administração do pecado original, é uma opinião que tem por trás de si uma respeitável história secular e que em si não é nem verdadeira, nem falsa. Ela é falsa hoje (FORTINI, 1974, p. 63). ${ }^{11}$

Fortini está rebatendo, de maneira indiretamente direta, a gravidade com que Pasolini compreende as consequências históricas observadas, as quais não são a priori nem verdadeiras, nem falsas, mas sim falsas nesse contexto. Isto é, não que seu ponto de vista não esteja fundamentado ou que não haja por trás dele "uma respeitável história secular" que possa corroborar as suas análises, mas Fortini (1974, p. 63) acredita haver sinais de que "a verdade política, em uma forma ainda inominável, está renascendo em outra parte das relações humanas ou do mundo". ${ }^{12}$ Por isso, se a história já estava dada por acabada, há tanto tempo, no poema de Pasolini, Fortini, por sua vez, acredita que esse não seria o fim da nossa história, da história da humanidade, mas sim o fim de uma história, da sua história - da realidade histórica compartilhada por ambos. Seria preciso então se distanciar dessa história do passado para que fosse possível estar atento ao presente, evitando-se cair na armadilha de generalizar o fim da história de uma geração, do mundo como esses intelectuais o conheceram, tomando as mudanças como sinais do fim de toda a história.

Passam-se duas semanas até que Pasolini retorne aos jornais, em uma entrevista dada a Guido Vergani, e responda, em 11 de julho de 1974, no jornal Il Mondo, aos textos que rebatiam as suas colocações. O título dessa nova publicação é mais uma vez um forte indício das relações que se estabeleceram na ocasião: "Queridos inimigos, vocês erraram" [Cari nemici, avete torto], ${ }^{13}$ com o subtítulo "Pier Paolo Pasolini responde às acusações” [Pier Paolo Pasolini risponde alle accuse]. Tenha sido um título dado pelo jornal ou um título escolhido pelo próprio Pasolini, é fato que existe aí uma ambiguidade que se estabelece quando pensamos em “inimigos queridos": queridos porque, ainda que sejam intelectuais que

\footnotetext{
11 "L'opinione di chi non crede alla percorribilità di una via politica fuor di quella dello scetticismo intellettuale o della amministrazione del peccato originale, è opinione che ha dietro di sé una rispettabile storia secolare e che in sé non è né vera né falsa. È falsa oggi." ${ }_{12}$ "[...] la verità politica, in una forma ancora innominata, sta rinascendo in altra parte dei rapporti umani o del mondo."

13 "Cari nemici, avete torto" (Il Mondo, 11 de julho de 1974, pp. 20-21). Em Scritti corsari, "Ampliamento del 'bozzetto' sulla rivoluzione antropologica in Italia” (PASOLINI, 1999, pp. 325-335); em Escritos corsários, "Ampliação do 'esboço' sobre a revolução antropológica na Itália” (PASOLINI, 2020, pp. 90-96).
}

Remate de Males, Campinas-SP, v.40, n.2, pp. 526-545, jul./dez. 2020 - 533 
tenham pontos de vista diferentes e discordem publicamente sobre eles, é preciso neutralizar (no sentido de não projetar nessas interlocuções uma agressividade que é marcante para nós na atualidade, mas não para eles) os possíveis embates e inimizades que surjam daí. Escrever em discordância é, nesse sentido, uma característica intrínseca à dinâmica de estímulos e respostas via jornais, ainda que o lado pessoal pese mais ou menos, a depender dos participantes do debate. Essa dinâmica se faz então presente no discurso jornalístico desses intelectuais, externalizando-se por meio de escolhas lexicais, como inimigos e acusações.

No referido colóquio, Pasolini discorre, a partir de algumas perguntas, sobre os temas que já havia abordado no artigo do Corriere e também comenta as reações que se deram após essa publicação. Em dado momento, menciona especificamente as intervenções veiculadas no L'Espresso e declara ao entrevistador que

[...] a obstinação de Fortini em querer estar sempre no ponto mais avançado daquilo que se chama história - fazendo isso pesar muito sobre os outros - me dá um instintivo sentimento de tédio e de prevaricação. Eu deixarei de "dizer que a história não existe mais" quando Fortini deixar de falar com o dedo em riste (PASOLINI, 2020, pp. 92-93). ${ }^{14}$

Pasolini não concorda com as constatações de Fortini, entendendo que as declarações dele são uma forma de sobrepor a sua versão de história como sendo a mais avançada ou a mais correta. Recria-se, assim, a imagem do pensador com o dedo em riste, apontando para cima; no entanto, diferentemente de Platão em "Escola de Atenas", ${ }^{15}$ que com a mão livre aponta para o alto em sinal do seu reconhecimento em se perceber mortal e em estar abaixo do que está acima, o dedo levantado de Fortini representaria a presunção e a arrogância de quem acredita que

\footnotetext{
${ }_{14}$ “[...] l'accanimento di Fortini a voler star sempre sul punto più avanzato di ciò che si chiama storia - facendo molto pesare ciò sugli altri - mi dà un istintivo senso di noia e di prevaricazione. Io smetterò di 'dire che la storia non c'è più' quando Fortini la smetterà di parlare col dito alzato" (PASOLINI, 1999, pp. 327-328).

15 "Rafael, na sua Escola de Atenas, representou o divino Platão que, com o Timeu numa mão, caminha solene pelo meio do pórtico, como um desses ideais apontadores de dedo; o pensador levanta significativamente a mão livre até acima e aponta o dedo a tudo o que 'aí em cima' é o caso. A sua referência aponta ao mundo urânico das ideias, do qual o 'nosso' mundo representa uma projeção ofuscada mais abaixo. O apontar de dedo de Platão dirige-se, praticamente, de forma crítica, de baixo para cima, daqui para ali - como o gesto de um homem que, indubitavelmente, esteve 'aí' uma e outra vez, mas que agora é, de novo, um dos nossos de cá de baixo, na penumbra da região dos mortais - supõe-se que para oficiar a missão de auxiliador de transição" (SLOTERDIJK, 2008, pp. 136-137).
}

Remate de Males, Campinas-SP, v.40, n.2, pp. 526-545, jul./dez. 2020 - 534 
a sua concepção de história é a única concepção possível. Pasolini não retrocede, por isso, em sua opinião sobre a história não existir mais e diz ainda que poderia usar a intervenção de Fortini a seu favor, entendendo o gesto como um "ascético convite para continuar trabalhando também para as ínfimas minorias; ou, quem sabe, esperar que as 'semelhanças' de hoje se tornem 'diferenças' amanhã” (PASOLINI, 2020, p. 92). ${ }^{16}$

\section{OS ROMPIMENTOS DE 1968}

Nesse ponto em que a relação entre Pasolini e Fortini passa a ganhar novas nuanças, valeria a pena voltar alguns anos nesse enredo. $\mathrm{Na}$ verdade, esse não foi o primeiro debate coletivo organizado por L'Espresso em resposta a uma polêmica ao redor de Pasolini. Em 1968, a famigerada publicação de seu poema “O PCI aos jovens!!” [Il PCI ai giovani!! ${ }^{17}$ viria acompanhada por um debate entre ele, Vittorio Foa, Claudio Petruccioli e representantes do movimento estudantil. O título jornalístico dado à publicação, "Eu odeio vocês, queridos estudantes" [Vi odio cari studenti], é exibido em destaque tanto na capa, quanto na parte interna do jornal e revela mais uma vez a ambiguidade de se colocar lado a lado os sentimentos de ódio e de afeto. O poema aparece, por sua vez, totalmente descaracterizado, sem versos ou métricas, e deslocado em relação à ordem natural da leitura: os olhos do leitor percorrem primeiro o debate ao redor do poema e só depois alcançam o poema em si (Figura 2).

16 "[...] ascetico invito a continuare a lavorare anche per delle infime minoranze; o magari anche sperare che le 'somiglianze' di oggi divengano 'differenze' di domani” (PASOLINI, 1999, p. 327).

${ }_{17} \mathrm{Na}$ época, o poema foi publicado, em partes ou integralmente, nos periódicos Nuovi Argomenti (n. 10, abril-junho de 1968), L'Espresso (16 de junho de 1968) e Paese Sera (12 de junho de 1968). Em livro, está recolhido em Empirismo eretico (1972), onde recebeu o título completo que havia aparecido em Nuovi Argomenti: "Il PCI ai giovani!! (Appunti in versi per una poesia in prosa seguiti da una 'Apologia')" (PASOLINI, 2014, vv. 439-468). Para uma análise sobre esse acontecimento, ver artigo de Maria Betânia Amoroso, "Pasolini e 68: II PCI aos jovens!" (Terceira Margem, v. 12, 2008, pp. 8-15). 

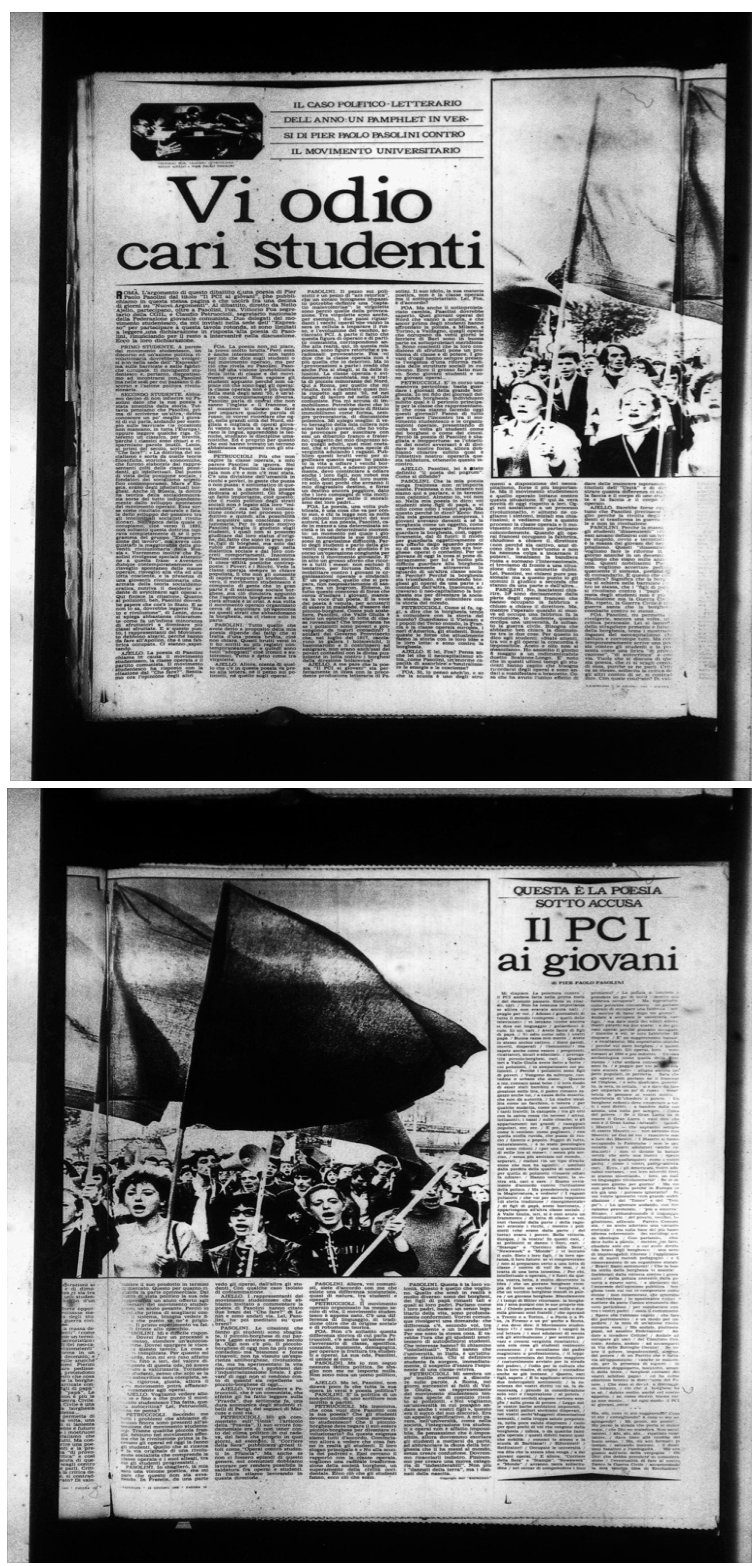

Figura 2 - Vi odio cari studenti”; publicação do poema “Il PCI ai giovani!!” em L’Espresso, (PASOLINI, 1968).

Fonte: Cópias feitas pela autora.

Na semana seguinte, dessa vez sob o título de "As cinzas de Pasolini" [Le ceneri di Pasolini], o L'Espresso publica um novo debate envolvendo outros escritores e intelectuais (Figura 3), entre eles Fortini, que vê em 
toda essa polêmica um exemplo entre os "falsos escândalos" aos quais os literatos frequentemente fazem coro.

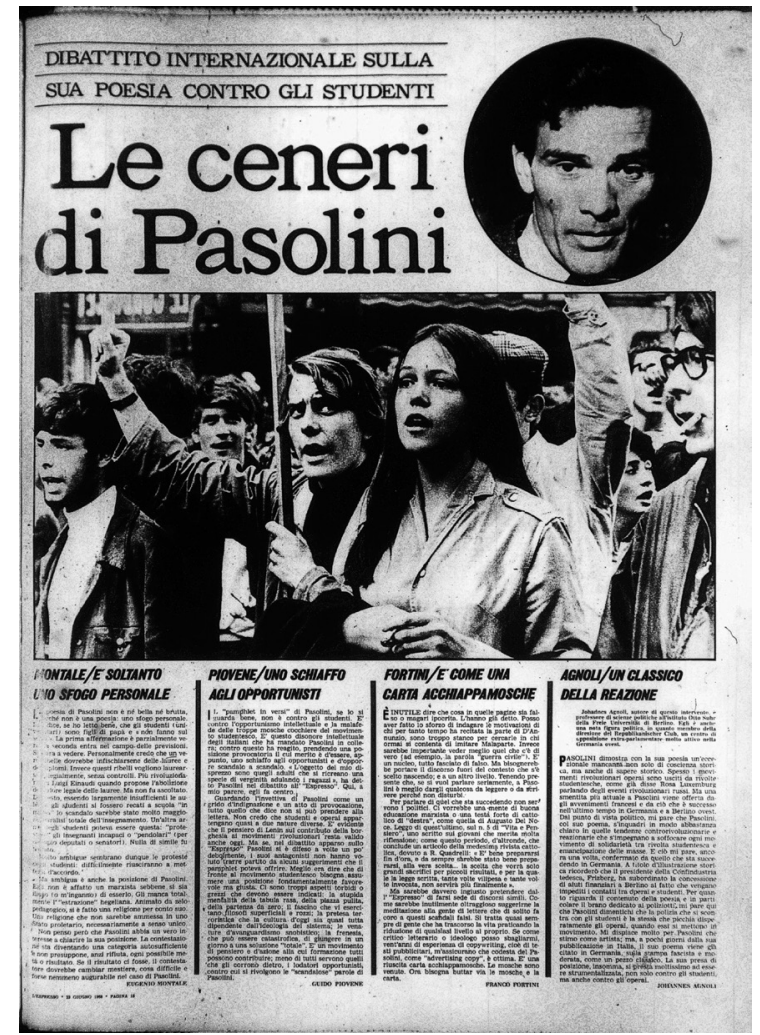

Figura 3 - "Le ceneri di Pasolini”; debate em L'Espresso (MORAVIA et al., 1968).

Fonte: Cópia feita pela autora.

Para o escritor, seria preciso alguém com uma boa educação marxista ou com uma forte formação de direita católica para tratar do que estava acontecendo. Porém, ele ainda afirma que

Seria realmente injusto esperar do L'Espresso que hospedasse discursos como esses. Assim como seria inutilmente ultrajante sugerir que a reflexão sobre esses temas fosse feita pela gente de letras que, frequentemente, faz coro a tais falsos escândalos. Trata-se quase sempre de gente que passou a vida reduzindo discussões de qualquer nível a si própria (FORTINI, 1968, p. 15). ${ }^{18}$

${ }_{18}$ "Ma sarebbe davvero ingiusto pretendere dall'Espresso di farsi sede di discorsi simili. Come sarebbe inutilmente oltraggioso suggerirne la meditazione alla gente di lettere che di solito fa coro a questi scandali falsi. Si tratta quasi sempre di gente che ha trascorso la vita praticando la riduzione di qualsiasi livello al proprio." 
A ideia de que literatos seriam incapazes de refletir sobre um tema pertinente à sociedade, afinal eles tendem a sempre reduzir questões sociais a suas próprias preocupações, é essencial para entendermos os pressupostos de Fortini quando reflete sobre a escolha pasoliniana de publicar o citado poema; ou seja, um pensamento que se volta mais a quem poderia publicar uma reflexão desse tipo ou à própria intenção de publicar o poema, ao invés de debater o texto em si. De certo ponto de vista, o ano de 1968 e a controversa publicação são então fundamentais para compreender a relação público-privada entre Pasolini e Fortini, pois foi nesse momento que eles romperam relações - ainda que, é preciso lembrar, essa tenha sido uma amizade sobretudo epistolar, já que Pasolini morava em Roma e Fortini, em Milão, e os dois se corresponderam ao longo dos anos 1950 e 1960 principalmente por meio de cartas e telefonemas.

O rompimento é relatado pelo próprio Fortini quando, em 1993, ou seja, quase 20 anos após a morte de Pasolini, ele retorna às trocas que estabeleceu com o poeta ao longo de sua vida e decide organizar o livro Attraverso Pasolini, no qual reúne e comenta todos os textos que escreveu sobre o autor até aquele momento. Mais do que para rememorar a relação de amizade intelectual que haviam mantido enquanto Pasolini ainda era vivo, Fortini (1993, p. VII) volta a esses textos em uma tentativa de retomar o ilusório conflito que existiu entre eles". Ilusório porque, em suas próprias palavras, a passagem do tempo sempre revela a pequenez de certos desentendimentos. Isso quer dizer que, no fim das contas, ambos estavam em busca de um mesmo ideal, movidos por reflexões muito similares, inspiradas em modelos marxistas e gramscianos, ${ }^{19}$ ainda que essa busca tenha seguido por trajetórias diferentes ao longo do tempo e

${ }^{19}$ Em entrevista ao escritor Alberto Arbasino, em 1963, Pasolini diz: "l'unico antenato spirituale che conta è Marx, e il suo dolce, irto, leopardiano figlio, Gramsci” [o único antepassado espiritual que conta é Marx e o seu doce, eriçado, leopardiano filho, Gramsci] (PASOLINI, 1999, p. 1.573). A relação entre Pasolini, e também entre essa geração de intelectuais, e o pensamento de Marx e Gramsci é de grande importância para o tema, porém tal aprofundamento escapa ao escopo deste artigo. Sendo assim, para uma discussão mais ampla, indicam-se, entre outros, os trabalhos de Paolo Desogus (por exemplo, Laboratorio Pasolini. Macerata: Quodlibet, 2018), na Itália; e, no Brasil, de Gesualdo Maffia (por exemplo, Pasolini crítico militante: de Passione e ideologia a Empirismo eretico. São Paulo: Nova Alexandria, 2019) e Alex Calheiros (por exemplo, a entrevista "A força extemporânea de Pasolini, um trágico moderno", publicada na Revista $I H U$, n. 504, maio de 2017, pp. 28-31). Sobre Fortini, ver a análise de Giuseppe Palazzolo em "Franco Fortini, ospite ingrato di quotidiani e riviste" (in SERAFINI, 2010, pp. 547-559).

Remate de Males, Campinas-SP, v.40, n.2, pp. 526-545, jul./dez. 2020 - 538 
gerado desentendimentos que se justificariam apenas pela ilusão de uma reação imediata.

Para Fortini, passados os anos, teria ficado claro que

[...] em suma, aqueles argumentos não diziam respeito ao escritor e ao poeta, nem mesmo à sua ou à minha biografia: mas à nossa existência, isto é, ao sentido de estarmos no mundo, os nossos deveres, as nossas escolhas. Não o seu ou o nosso trabalho: mas o modo como foram vividos e queimados alguns decênios (FORTINI, 1993, p. X). ${ }^{20}$

Nessa passagem, o escritor se identifica com Pasolini e reconhece a ambos esse lugar de intelectuais que pertenceram à mesma geração, que viveram a mesma experiência histórica e que, por isso, acabaram por ter existências parecidas - o que implicaria um mesmo modo de vida, movido pelos mesmos valores. Porém, Fortini ainda completa, esse reconhecimento não se dá sem alguma ironia por saber que, na realidade, é escassa "a importância dos feitos de grupos intelectuais e literários” (FORTINI, 1993, p. X). ${ }^{21}$

Entretanto, se à distância dos anos Fortini é capaz de se reconhecer no empenho ideológico praticado por Pasolini, isso não significa que em vida ambos seguiram as mesmas práticas intelectuais. Em uma das cartas de Fortini a Pasolini, também recolhida nessa espécie de livro-memória organizado pelo escritor florentino, ele formula o sintagma "discurso crítico". Ao se referir a um conjunto de poemas que havia enviado para apreciação da revista literária Officina,${ }^{22}$ da qual era colaborador, está defendendo a ideia de que "um discurso orgânico só pode ser um discurso crítico e não autobiográfico” (FORTINI, 1993, p. 59). ${ }^{23}$ Essa é uma chave

20 "Quegli argomenti non riguardavano insomma lo scrittore e il poeta e neanche la sua o mia biografia: ma la nostra esistenza ossia il senso del nostro essere al mondo, i nostri compiti, le scelte. Non quel suo lavoro o il nostro: ma il modo in cui vennero vissuti e bruciati alcuni decenni. Dico questo pur invocando l'ironia di chi sa quanto sia scarsa, in realtà, l'importanza delle vicende di gruppi intellettuali e letterari. E anche con tutta la rabbia di non aver saputo con bastante energia rifiutare la ridicola e non innocente enfiagione dei ruoli che il potere - o l'antipotere, che del primo non di rado è complice attribuisce alle corporazioni delle arti e delle lettere."

${ }_{21}$ "[...] l'ironia di chi sa quanto sia scarsa, in realtà, l'importanza delle vicende di gruppi intellettuali e letterari”.

${ }^{22}$ Revista literária fundada, em 1955, por Pasolini, Francesco Leonetti e Roberto Roversi, em Bolonha. Para mais informações sobre a fundação da revista e seus desenvolvimentos, cf. Gian Carlo Ferretti, "Officina": cultura, letteratura e politica negli anni cinquanta (Turim: Editora Einaudi, 1975).

${ }_{23}$ "[...] un discorso organico può essere solo un discorso critico e non autobiografico".

Remate de Males, Campinas-SP, v.40, n.2, pp. 526-545, jul./dez. 2020 - 539 
importante para entendermos o seu pensamento. Em primeiro lugar, porque seu envolvimento com a revista é permeado pela vontade de Fortini de, nas suas palavras, "induzir os novos amigos a um maior rigor ideológico” (p. 134) ${ }^{24}$ - o que revela um conflito de rigores que o levaria, em determinado momento, a deixar de colaborar com a revista. Além disso, em uma circunstância histórica voltada para a dedicação a refletir sobre as melhores formas de atuação política e intelectual após o fim da Segunda Guerra e do fascismo, Fortini exclui do horizonte do seu discurso crítico qualquer conciliação com o discurso autobiográfico. Assim, o paradigma do discurso de um intelectual orgânico passa, segundo ele, pela exclusão desse fator autobiográfico - algo que, se pensarmos na atuação de Pasolini, seria insustentável. Para o poeta de As cinzas de Gramsci, crítico e autobiográfico não são categorias que se opõem; pelo contrário, elas se complementam à medida que praticar a crítica orgânica é emaranhar-se no organismo social e histórico do qual se é sujeito. Fazer crítica e ser crítico seriam, para Pasolini, sinônimos de viver a sua própria realidade e, ao escrevê-la, ser contemporaneamente filtrado e ser filtro dessa realidade, inscrevendo-se então através dela.

Fortini, por sua vez, percebe esse tipo de imbricação com a própria obra por outro ponto de vista. No caso da publicação de "O PCI aos jovens!!", chega a declarar que estava desesperado com a atitude de Pasolini: "Mais do que o texto a favor dos policiais, o que eu achava insuportável era aceitar o aproveitamento publicitário e a inevitável transformação em propaganda vulgar daquele seu escrito" (FORTINI, 1993, p. 42). ${ }^{25} \mathrm{Ou}$ seja, dentro do paradigma de atuação por ele traçado, era inconcebível um escritor ceder sua própria obra e seu próprio engajamento intelectual àquele aproveitamento midiático, configurado a partir da publicação do poema. Por aproveitamento midiático, podemos pensar tanto nos indícios mais básicos de estímulo ao ódio e de sensacionalismo presentes no título e na diagramação de L'Espresso, quanto no debate posterior, no qual o periódico ainda colheria mais material para especulações.

No calor do momento, para tentar impedir que Pasolini publicasse o poema em L'Espresso, Fortini (1993, p. 41) conta que leu para o amigo uma nota em que discorria sobre os motivos que o levavam a desacreditar

\footnotetext{
24 "Mi pareva di poter indurre i nuovi amici ad un maggior rigore ideologico."

25 "Ero davvero esasperato dal suo atteggiamento; ben più che per il testo a favore dei poliziotti, quel che trovavo insopportabile era di accettare lo sfruttamento pubblicitario, e la inevitabile trasformazione in volgare propaganda, di quel suo scritto.”
} 
essa forma de atuação e que, por isso, desencorajava-o a publicar o poema em um periódico como aquele:

\begin{abstract}
Você peca pela presunção. Acreditou poder cavalgar, um depois do outro, todos os tigres do poder comunicativo. Não bastava a você ser um D’Annunzio, você quis ser também Malaparte. Com o ímpeto da sua genialidade é possível fazer muitas coisas. Mas não se pode fazer aquela única coisa que permite sair do esteticismo em direção à história e à política: a renúncia real, não verbal, ao monólogo e aos prazeres do narcisismo. ${ }^{26}$
\end{abstract}

Se retomarmos o comentário de 1974 direcionado aoartigo "Os italianos não são mais os mesmos", quando Fortini exclui de sua argumentação qualquer referência pessoal a Pasolini ao responder a ele, anos após o rompimento entre os dois, veremos aí um reflexo desse desentendimento. Em total oposição à maneira pela qual Pasolini passou a fazer crítica por meio de escritos publicados em periódicos de grande circulação, isto é, nos "tigres do poder comunicativo", Fortini identifica nessa prática um discurso monológico e narcisista, sem aquele rigor ideológico pelo qual este primava, o que pouco contribui à atuação política e intelectual efetiva. Para Pasolini, por outro lado, a interlocução direta, que perpassa a vida de quem escreve e para quem se escreve, é o instrumento de uma crítica que acredita na importância de - recorrendo aqui a um dos refrões pasolinianos - "jogar o próprio corpo na luta" [gettare il proprio corpo nella lotta].

\title{
OUTRAS CONSIDERAÇÕES
}

É possível então notar que as perspectivas de atuação intelectual de Pasolini e Fortini eram formalmente distintas, mas ambas estavam bastante ligadas a um tempo e a um espaço específicos e respondiam ideologicamente ao momento histórico em que foram concebidas. Pasolini e Fortini, assim como outros intelectuais contemporâneos a eles, pertenciam a uma mesma geração e se questionavam simultaneamente sobre as possibilidades de seu fazer intelectual e literário. Nos anos 1970, eles se deparavam ainda com um mundo já desiludido com o fracasso da União Soviética, enquanto se empenhavam em defrontar os diversos flertes com as novas formas de fascismo que surgiam. Tencionavam, por

\footnotetext{
26 "Hai peccato di presunzione. Hai creduto di poter cavalcare una dopo l'altra tutte le tigri del potere comunicativo. Non ti bastava essere D’Annunzio, hai voluto essere anche Malaparte. Con l'impeto della tua genialità si possono fare molte e bellissime cose. Ma non si può fare quella sola che permette di uscire dall'estetismo verso la storia e la politica: la rinuncia reale, non verbale, al monologo e ai piaceri del narcisismo."
} 
isso, a ideia de um discurso crítico ao limite, para enfim pensar em que medida ele poderia ou não ser efetivo no combate a um projeto político e econômico que destruiria o mundo e a história que eles conheciam.

Por isso, a expressão pasoliniana "jogar o meu corpo na luta" [gettare il mio corpo nella lotta] poderia, nesse sentido, ser entendida como uma tentativa extrema de manter alguma crença na recuperação desse mundo e dessa geração que eles viam desaparecer. Ela aparece, provavelmente, pela primeira vez ${ }^{27}$ no "poema bio-bibliográfico" - assim definido pelo próprio Pasolini -, de 1966, chamado "Poeta delle ceneri”, publicado originalmente no periódico Nuovi Argomenti, em 1980, e depois reunido no volume Tutte le poesie da obra completa. Há ali uma longa retomada de acontecimentos da vida de Pasolini até aquele momento e a confissão de que era preciso encontrar novas formas para se expressar:

\author{
Por isso eu gostaria de viver apenas \\ mesmo sendo poeta \\ porque a vida também se expressa apenas através de si mesma. \\ Eu gostaria de me expressar com exemplos. \\ Jogar meu corpo na luta. \\ Mas se as ações da vida são expressivas, \\ a expressão também é ação \\ (PASOLINI, 1980, p. 25). ${ }^{28}$
}

\begin{abstract}
${ }^{27}$ Outra ocorrência da expressão se dá no artigo "Perché vado a Venezia", de agosto de 1968, em que o escritor diz: "Siamo d'accordo sul fatto che in certi momenti l'artista deve avere il coraggio civile di smettere di esprimersi attraverso la mediazione delle opere, ed esprimersi invece direttamente, attraverso la sua propria esistenza: cioè, 'gettare il proprio corpo nella lotta', come dice un meraviglioso slogan della Nuova Sinistra americana” [Estamos de acordo sobre o fato de que, em certos momentos, o artista deve ter a coragem civil de parar de se expressar por meio de suas obras e se expressar diretamente por meio de sua própria existência, isto é, "jogar seu próprio corpo na luta”, como diz o maravilhoso slogan da Nova Esquerda americana] (PASOLINI, 1999, p. 165). Além disso, no texto "Guerra civile", recolhido em Empirismo eretico, de 1972, o escritor explica melhor a origem da expressão a partir dos versos de um canto do Movimento de Resistência Negra estadunidense e completa: "Ecco il nuovo motto di un impegno, reale, e non noiosamente moralistico: gettare il proprio corpo nella lotta... Chi c'è, in Italia, in Europa, che scrive spinto da tanta e così disperata forza di contestazione? Che sente questa necessità di opporsi, come una necessità originaria, credendola nuova nella storia, assolutamente significativa, e piena insieme di morte e di futuro?" [Eis um novo mote de engajamento real, e não pedantemente moralístico: jogar o próprio corpo na luta... Quem, na Itália, na Europa, escreve movido por tamanha e tão desesperada força de contestação? Que sente esta necessidade de se opor como uma necessidade originária, acreditando ser nova na história, absolutamente significativa, e ao mesmo tempo cheia de morte e de futuro?] (PASOLINI, 2014, vv. 436-437).

28 "Perciò io vorrei soltanto vivere/ pur essendo poeta/ perché la vita si esprime anche solo con se stessa./ Vorrei esprimermi con gli esempi./ Gettare il mio corpo nella lotta./ Ma se le azioni della vita sono espressive,/ anche l'espressione è azione."
\end{abstract}

Remate de Males, Campinas-SP, v.40, n.2, pp. 526-545, jul./dez. 2020 - 542 
O pressuposto de que também há expressividade em apenas viver parece ser um dos pilares da reflexão de Pasolini acerca dessa forma de escrita em que o escritor se implica plenamente no que cria; em que seu corpo é matéria de sua escrita e, consequentemente, de sua ação. Retomando a discussão que viria a ocorrer com Fortini poucos anos depois da escrita desse poema, na qual o escritor florentino critica aqueles que se apropriam de uma discussão e a veem a partir de si mesmos, Pasolini parece encontrar justamente nessa possibilidade uma nova maneira de se expressar e de alcançar uma audiência cuja comunicação não poderia se dar mais apenas através da poesia.

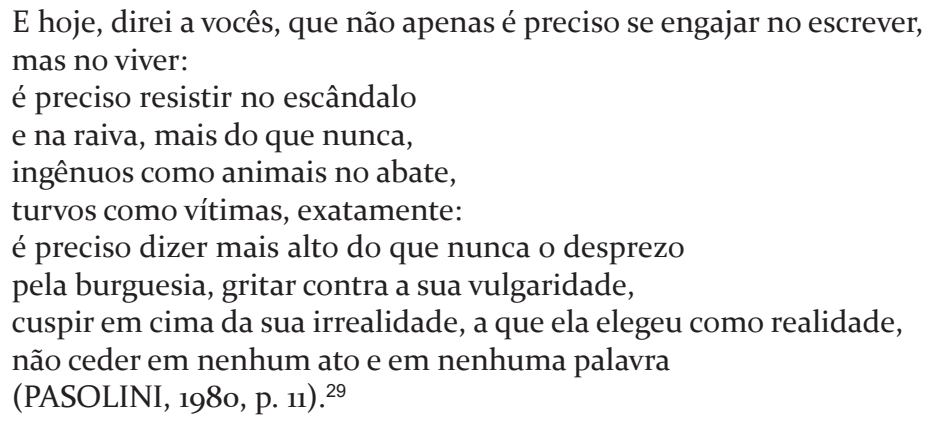

O escândalo da palavra escrita, segundo a visão pasoliniana, é a força de sua indignação diante do caos. É a revolta que emana de sua própria existência e da impossibilidade de simplesmente observar, sem agir, aquilo que o toca pessoalmente. Nesses termos, a palavra se transforma, torna-se ação, pois é canal para a raiva, para o desespero, para a consciência do fim de uma história. O poeta só pode, com sua palavra, não ceder a esse fim.

\section{$\overline{\text { REFERÊNCIAS }}$}

CALVINO, Italo. Una pietra sopra: discorsi di letteratura e società. Milão: Oscar Mondadori, 2018.

FORTINI, Franco (Org.). Profezie e realtà del nostro secolo: testi e documenti per la storia di domani. Bari: Laterza, 1965.

\footnotetext{
29 "E oggi, vi dirò, che non solo bisogna impegnarsi nello scrivere,/ ma nel vivere:/ bisogna resistere nello scandalo/ e nella rabbia, più che mai,/ ingenui come bestie al macello,/ torbidi come vittime, appunto:/ bisogna dire più alto che mai il disprezzo/ verso la borghesia, urlare contro la sua volgarità,/ sputare sopra la sua irrealtà che essa ha eletto a realtà,/ non cedere in un atto e in una parola."
} 
FORTINI, Franco. Ventiquattro voci: per un dizionario di lettere. Milão: Alberto Mondadori Editore, 1968.

FORTINI, Franco. È come una carta acchiappamosche. In: MORAVIA, Alberto et al. Le ceneri di Pasolini: dibattito internazionale sulla sua poesia contro gli studenti. L'Espresso, 23 jun. 1968, p. 15.

FORTINI, Franco. Ma smettila di dire che la storia non c'è più. In: É nato un bimbo, c'è un fascista in più. L'Espresso, 23 jun. 1974, pp. 61-63.

FORTINI, Franco. Attraverso Pasolini. Turim: Einaudi, 1993.

FORTINI, Franco. Saggi e epigrammi. Org. Luca Lenzini. Milão: Arnoldo Mondadori, 2003. (Coleção "I Meridiani”)

FORTINI, Franco. Tutte le poesie. Organização de Luca Lenzini. Livro digital. Milão: Oscar Mondadori, 2015.

MELO NETO, João Cabral de. Poesia Crítica: antologia. Rio de Janeiro: José Olympio, 1982.

MORAVIA, Alberto et al. Le ceneri di Pasolini: dibattito internazionale sulla sua poesia contro gli studenti. L'Espresso, 23 jun. 1968, pp. 14-15.

MORAVIA, Alberto et al. É nato un bimbo, c'è un fascista in più. L'Espresso, 23 jun. 1974, pp. 58-65.

PASOLINI, Pier Paolo. Gli italiani non sono più quelli. Corriere della Sera, 10 de junho de 1974a, pp. 1-2.

PASOLINI, Pier Paolo. Cari nemici, avete torto. Il Mondo, 11 de julho de 1974b, pp. 20-21.

PASOLINI, Pier Paolo. Le ceneri di Gramsci. Milão: Garzanti, 1976.

PASOLINI, Pier Paolo. Poeta delle ceneri. Nuovi Argomenti, v. 67-68, jul.-dez. 1980, pp. 3-29.

PASOLINI, Pier Paolo. Saggi sulla politica e sulla società. Org. Walter Siti e Silvia De Laude. ra edição. Milão: Mondadori, 1999.

PASOLINI, Pier Paolo. Empirismo eretico. Livro digital. Milão: Garzanti, 2014.

PASOLINI, Pier Paolo. Poemas: Pier Paolo Pasolini. Trad. Maurício Santana Dias. Org. Maurício Santana Dias e Alfonso Berardinelli. São Paulo: Cosac Naify, 2015.

PASOLINI, Pier Paolo. Escritos corsários. Trad. Maria Betânia Amoroso. São Paulo: Editora 34, 2020.

PASOLINI, Pier Paolo et al. Vi odio cari studenti. L'Espresso, 16 jun. 1968, pp. 12-13. 
PINA, Manuel António. O coração pronto para o roubo: poemas escolhidos. Seleção de Leonardo Gandolfi. São Paulo: Editora 34, 2018.

SERAFINI, Carlo (Org.). Parola di scrittore: letteratura e giornalismo nel Novecento. Roma: Bulzoni Editore, 2010.

SERAFINI, Carlo (Org.). Parola di scrittore: altri studi su letteratura e giornalismo. Roma: Bulzoni Editore, 2014.

SLOTERDIJK, Peter. O estranhamento do mundo. Lisboa: Relógio D’Água, 2008.

TURCHETTA, Gianni; ESPOSITO, Edoardo (Orgs.). Franco Fortini e le istituzioni letterarie. Milão: Ledizioni, 2018.

Recebido: 16/5/2020

Aceito: 19/8/2020

Publicado: 18/11/2020

Remate de Males, Campinas-SP, v.40, n.2, pp. 526-545, jul./dez. 2020 - 545 